\title{
Tratamento de rizóforos-semente de inhame infectados por Scutellonema bradys e Pratylenchus coffeae com manipueira
}

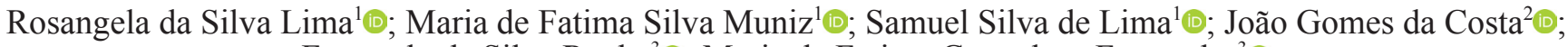 \\ Fernando da Silva Rocha ${ }^{3} \mathbb{0}$; Maria de Fatima Gonçalves Fernandes ${ }^{3} \mathbb{0}$
}

${ }^{1}$ Universidade Federal de Alagoas, Centro de Ciências Agrárias, CEP 57100-000, Rio Largo, AL, Brasil; ${ }^{2}$ Embrapa Tabuleiros Costeiros, CEP 57100000, Rio Largo, AL, Brasil; ${ }^{3}$ Universidade Federal de Minas Gerais, Instituto de Ciências Agrárias, CEP 39404-547, Montes Claros, MG, Brasil. Autor para correspondência: Maria de Fatima Silva Muniz (mf.muniz@uol.com.br)

Data de chegada: 07/03/2017. Aceito para publicação em: 28/11/2019

$10.1590 / 0100-5405 / 182175$

\section{RESUMO}

Lima, R.S; Muniz, M.F.S.; Lima, S.S.; Costa, J.G.; Rocha, F.S.; Fernandes, M.F.G. Tratamento de rizóforos-semente de inhame infectados por Scutellonema bradys e Pratylenchus coffeae com manipueira. Summa Phytopathologica, v.46, n.1, p.xx-xx, 2020.

Sob condições de casa de vegetação foram avaliadas as concentrações de manipueira 25,50 e $100 \%$ e dois períodos de imersão de 9 e $12 \mathrm{~h}$, além da testemunha, no tratamento de rizóforos-semente de inhame naturalmente infectados por Scutellonema bradys e Pratylenchus coffeae. O percentual de brotação dos rizóforos observado aos três meses após o plantio foi de $100 \%$ em todos os tratamentos. Aos cinco meses, as concentrações de manipueira nos dois períodos de imersão ( $25 \%$

- 9 horas; $25 \%$ e $50 \%$ - 12 horas), apresentaram os melhores resultados em relação à testemunha, para as populações finais dos nematoides/g de casca de rizóforos.

Palavras-chave: Casca-preta-do-inhame, Dioscorea spp., manejo.

\section{ABSTRACT}

Lima, R.S; Muniz, M.F.S.; Lima, S.S.; Costa, J.G.; Rocha, F.S.; Fernandes, M.F.G. Treatment of yam seed tubers infected by Scutellonema bradys and Pratylenchus coffeae with cassava wastewater. Summa Phytopathologica, v.46, n.1, p.53-55, 2020.

Under greenhouse conditions, cassava wastewater (manipueira) concentrations of 25,50 and $100 \%$, as well as two immersion periods ( 9 and $12 \mathrm{~h}$ ), besides a control, were evaluated for the treatment of yam seed tubers naturally infected by Scutellonema bradys and Pratylenchus coffeae. Tuber sprouting percentage at three months after planting was $100 \%$ for all treatments. At five months, manipueira concentrations in both immersion periods $(25 \%$ - 9 hours; $25 \%$ and 50\% -12 hours) led to the best results, compared to control, for the final populations of nematodes/g tuber peel.

Keywords: Dry rot of yam, Dioscorea spp., management.

No Brasil, a casca-preta do inhame (Dioscorea spp.) causada por Scutellonema bradys (Steiner \& LeHew) Andrássy, Pratylenchus coffeae (Zimmermann) Filipjev \& Schuurmans Steckhoven e $P$. brachyurus (Godfrey) Filipjev \& Schuurmans Stekhoven representa o problema fitossanitário mais importante da cultura (9). No Ministério da Agricultura não existem nematicidas registrados para a cultura do inhame. Assim, produtos alternativos tais como a manipueira, resíduo líquido da industrialização da mandioca (Manihot esculenta Crantz), vem sendo testada no País. O objetivo deste trabalho foi avaliar o potencial de manipueira no tratamento de rizóforos-semente de inhame naturalmente infectados por nematoides causadores da casca-preta.

Para determinação da população inicial (Pi) dos nematoides, foram processadas $1 \mathrm{~g}$ da casca de cada rizóforo-semente (4). A seguir, realizouse a identificação $(6,8)$ e a quantificação. A manipueira foi obtida da cultivar Sergipana com teor de cianeto estimado pelo teste colorimétrico Quantofix ${ }^{\circledR} \mathrm{em} 3 \mathrm{mg} \mathrm{L}^{-1}$. Os rizóforos foram imersos nas concentrações de 25,50 e $100 \%$ por períodos de 9 e $12 \mathrm{~h}$, além da testemunha (sem imersão) e cultivados em vasos de $8 \mathrm{~L}$ de capacidade contendo solo esterilizado. O delineamento foi inteiramente casualizado em esquema fatorial com cinco repetições, sendo cada uma, representada por um rizóforo. Após três meses, avaliou-se o percentual de brotação (PB), e no quinto mês, a Massa Fresca da Casca dos Rizóforos (MFCR) e Massa Fresca do Sistema Radicular (MFSR). A população final dos nematoides foi estimada em $100 \mathrm{~cm}^{3}$ de solo (7) e nas raízes e casca dos rizóforos (4).

Os dados foram submetidos ao teste de Kruskal-Wallis por meio do uso da função kruskal.test ( ) do programa estatístico R, versão 3.2.4 (11). Como teste post hoc foi realizado o teste de Kruskal-Wallis para comparações múltiplas, utilizando a função kruskal ( ), do pacote agricolae para o $\mathrm{R}$, a $\alpha=0,05$ de significância e ajustamento para testes múltiplos dos p-valores por meio do método de Bonferroni (1). Foram considerados estatisticamente significativos valores de $\mathrm{p}<0,05$.

A avaliação da Pi mostrou a ocorrência simultânea de $S$. bradys e $P$. coffeae (44 a 384 indivíduos/g da casca de rizóforos). A análise estatística não foi significativa $(\mathrm{p} \leq 0,05)$, demonstrando a uniformidade das populações dos nematoides nos rizóforos. O PB dos rizóforos foi de $100 \%$. Os tratamentos com os tempos de imersão de $9 \mathrm{~h}$, nas concentrações de manipueira de 25 e $50 \%$ proporcionaram os maiores valores de MFSR, comparado à concentração de 100\% (Figura 1A). Para a MFCR não ocorreu diferença significativa entre os tratamentos. Dados representativos foram observados nas menores concentrações de manipueira nos dois períodos de imersão $(25 \%$ - 9 h; $25 \%$ e $50 \%$ - 12 h), para as populações finais dos nematoides/g de casca de rizóforos, comparado à testemunha (Figura 1B). Segundo Coyne \& Affokpon (5) o nível populacional de $S$. bradys de 20 espécimes/g de casca de rizóforos é suficiente para provocar prejuízos. Não foram verificadas 

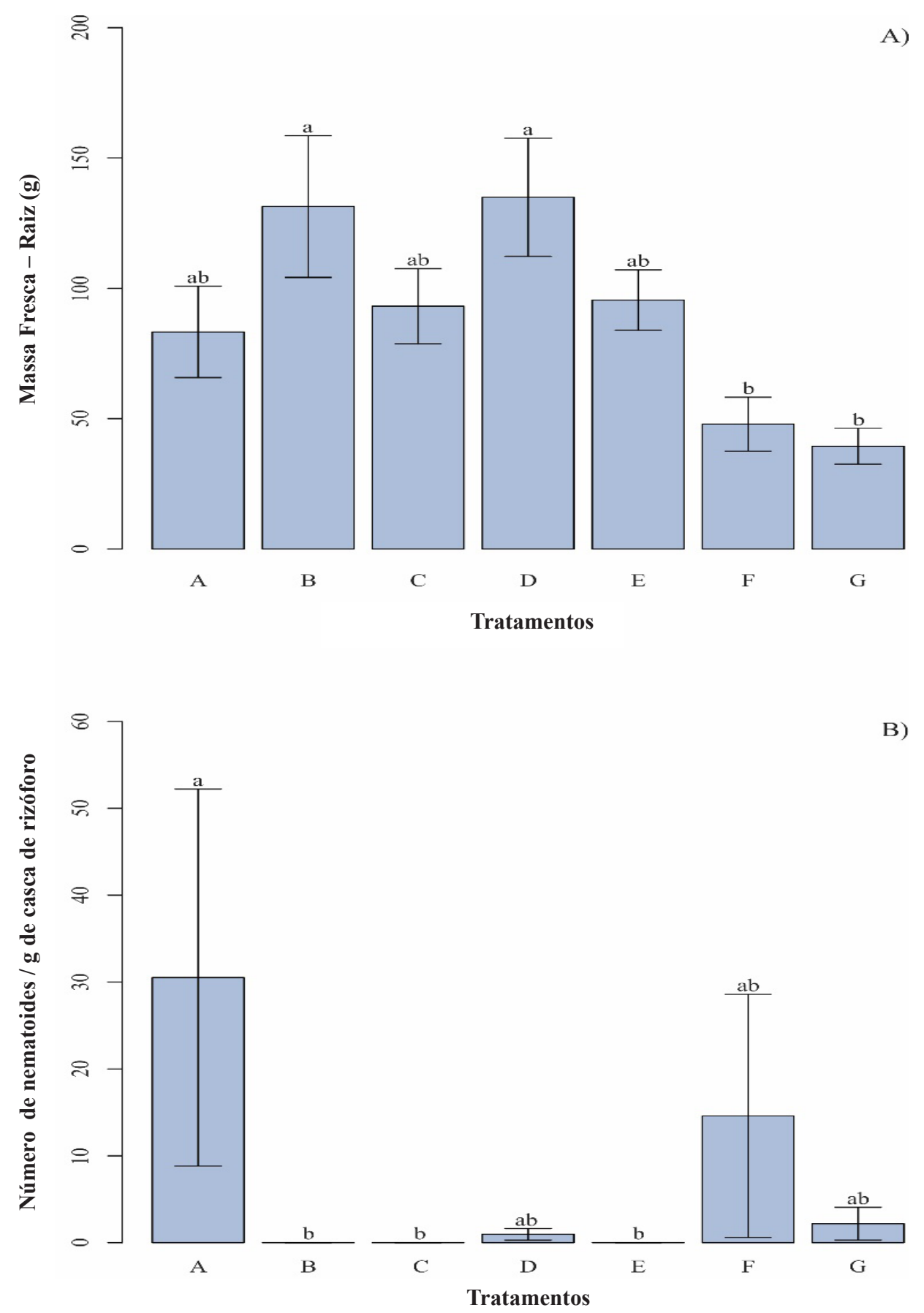

Figura 1. Massa fresca do sistema radicular (A) e número de nematoides/g de casca de rizóforo (B) após o tratamento do material de propagação com diferentes concentrações de manipueira e tempos de imersão. Tratamentos: $\mathrm{A}=$ testemunha, $\mathrm{B}=25 \%+9$ horas, $\mathrm{C}=25 \%+12$ horas, $\mathrm{D}=$ $50 \%+9$ horas, $\mathrm{E}=50 \%+12$ horas, $\mathrm{F}=100 \%+9$ horas, $\mathrm{G}=100 \%+12$ horas. Médias seguidas de mesma letra não diferem entre si pelo teste de Kruskal-Wallis ( $\alpha=0,05$ de significância).

diferenças significativas para número de nematoides/g de raiz e solo.

A eficácia da manipueira no controle de espécies de Meloidogyne por meio da aplicação de cianeto nas concentrações de 25 a $40 \mathrm{mg} \mathrm{L}^{-1}$ via solo tem sido relatada $(3,10)$. No presente trabalho o teor de cianeto foi de $3 \mathrm{mg} \mathrm{L}^{-1}$, mas informações sobre a dose letal a fitonematoides é carente na literatura científica. Os resultados obtidos neste estudo concordam parcialmente com o trabalho de Carmo (2), que verificou uma redução de $S$. bradys em raízes de plantas de inhame, após a imersão por 6 a 15 h de rizóforos-semente infectados em manipueira a $100 \%$. A aplicação de manipueira via tratamento do material de propagação poderá evitar a introdução e a disseminação dos nematoides causadores da casca-preta. 


\section{AGRADECIMENTOS}

O presente trabalho foi realizado com apoio da CAPES - Código de Financiamento 001. Ao CNPq, pelo apoio financeiro (Processo 446760/2014-5).

\section{REFERÊNCIAS}

1. Bonferroni, C.E. Teoria statistica delle classi e calcolo delle probabilità. 8.ed. Firenze: Pubblicazioni del R Istituto Superiore di Scienze Economiche e Commerciali di Firenze, 1936.

2. Carmo, D.O. Gama de plantas hospedeiras e controle do nematoide do inhame, Scutellonema bradys, com manipueira. 2009. 53f. Dissertação (Mestrado em Fitotecnia) - Centro de Ciências Agrárias, Ambientais e Biológicas, Universidade Federal do Recôncavo da Bahia, Cruz das Almas.

3. Carvalho, P.H. Controle biológico e alternativo de Meloidogyne incognita e M. javanica em tomateiro. 2017. 98f. Dissertação (Mestrado em Fitopatologia) - Instituto de Ciências Biológicas, Universidade de Brasília, Brasília, DF.

4. Coolen, W.A.; D'Herde, C.J. A method for the quantitative extraction of nematodes from plant tissue. Ghent: State Agricultural Research Centre, 1972. $77 \mathrm{p}$
5. Coyne, D.; Affokpon, A. Nematodes parasites of tropical root and tuber crops (excluding potatoes). In: Sikora, R.A.; Coyne, D.; Hallmann, J.; Timper, P. (ed.). Plant parasitic nematodes in subtropical and tropical agriculture 3.ed. Boston, MA: CABI, 2018, cap.8, p.252-289.

6. Gonzaga, V.; Santos, J.M.; Mendonça, R.S.; Santos, M.A. Gênero Pratylenchus. In: Oliveira, C.M.G.; Santos, M.A.; Castro, L.H.S. (org.). Diagnose de fitonematoides. Campinas: Millennium Editora, 2016. p.71-98.

7. Jenkins, W.R. A rapid centrifugal-flotation technique for separating nematodes from soil. Plant Disease Reporter, St. Paul, v.48, n.9, p.692, 1964

8. Mai, W.F.; Mullin, P.G. Plant-parasitic nematodes: a pictorial key to genera. 5th ed. New York: Cornell University, 1996. 277p.

9. Moura, R.M. Doenças do inhame-da-Costa. In: Amorim, L.; Rezende, J.A.M.; Bergamin Filho, A.; Camargo, L.E.A. (ed.). Manual de fitopatologia: doenças das plantas cultivadas. 5.ed. Ouro Fino: Agronômica Ceres, 2016. v.2, cap.49, p.477-483.

10. Nasu, E.G.C.; Formentini, H.M.; Furlanetto, C. Effect of manipueira on tomato plants infected by the nematode Meloidogyne incognita. Crop Protection, Guildford, v.78, p.193-197, 2015.

11. R Development Core Team. R: A language and environment for statistical computing. Vienna R Foundation for Statistical Computing, 2016. Disponível em: <http://www.R-project.org>. Acesso em: 2 mar. 2017. 